\title{
THE METHODS OF TEACHING AND LEARNING IN THE ASPECT OF SYNERGISTIC THEORY
}

\author{
NELI SESADZE \\ PhD, Professor \\ Georgian National University, Georgia \\ nelisesadze@seu.edu.ge
}

\author{
VALIDA SESADZE \\ Doctor of Technical Science \\ Georgian Technical University, Georgia \\ V_sesadze@gtu.ge
}

\section{ANZORI KEVKHISHVILI}

PhD, Student

Georgian Technical University, Georgia

akevkhishvili@gmail.com

Abstract. Modern education is a very complex system that exists in an unstable society. Therefore, it would be useful to consider the problem of human education from the standpoint of a synergistic approach. Self-study and mutual learning of students take place as a part of small permanent student groups. The project is considered completed if each student is a member of the team in equal degree explains the solution to the problem and answers all questions of the teacher. Synergistic effect is expressed in a change in the attitude of students to study, an increase in motivation to acquire knowledge, the formation of abilities for self-learning and mutual learning, the ability to find effective ways of solving problems.

\section{KEYWORDS: SYNERGETIC THEORY, SELF-ORGANIZATION, SYNERGISTIC EFFECT,}

PROJECT DEVELOPMENT AND PRESENTATION.

For citation: Sesadze, N., Sesadze, V., Kevkhishvili, A., (2021). The Methods of Teaching and Learning in the Aspect of Synergistic Theory. Globalization and Business, №11, 108-111. https://doi.org/10.35945/gb.2021.11.015

\section{INTRODUCTION}

The developed world has gone through both agricultural and industrial and post-industrial stages of the economy. The knowledge economy is considered to be the last stage in the development of the global economy. Today knowledge accompanies any activity. Innovations are becoming a key resource for job creation and employment growth. Today the world invests more in the field of knowledge than in major funds.

States' spending on human capital formation is increasing. Expenditure on education in European countries is more than $5 \%$ of GDP. State budget expenditures on education are increasing in Georgia. The index increased from $2.8 \%$ to $3.6 \%$ in 2010-2019. By 2022, according to the state budget, these expenditures will be equal to $22 \%$ of GDP.

Today, both labor supply and demand in the labor market are characterized by problems. International studies con- firm the problems of the quality of the education system in Georgia and the low skills of the workforce. With this indicator, Georgia lags behind the post-Soviet countries - in terms of workforce skills, it takes the $125^{\text {th }}$ place among 141 countries by 2019 ..

The problems of the education system have been exacerbated by the pandemic and the associated special coercive measures.

The COVID-19 pandemic has affected all areas of public life, including the education system. One of the ways to contain coronavirus infection is social isolation, its measures required the closure of educational institutions.

The pandemic has become a catalyst for change in this area. Educational leaders almost immediately faced a difficult choice: to try to translate educational processes into an online environment.

Despite a fairly wide range of available technologies, even the leading countries in the field of digitalization of the 
economy (USA, China, Japan) experience significant difficulties in organizing online education.

It is not the lack of infrastructure or the lack of readiness of teachers to master digital learning technologies that is difficult; the current situation is radically changing the existing model of social interaction communication between students and teachers is moving to a new format.

Accelerated digitalization is becoming a test of the strength of teachers, educational institutions, and national educational systems.

This situation in the labor market is caused by many factors, but in this article, we will focus only on teaching-learning methods, through which we consider it is possible to increase the motivation of students to study. We discuss the problem of increasing motivation from the position of synergistic theory.

\section{THE MAIN PART}

In the middle of the XX century a new direction of science emerged - synergy, which attracted the attention of a wide circle of scientists, because it was about a range of problems that were relevant to both the natural sciences and the humanities. Synergistic studies general patterns in the self-organization of complex systems.

In the frame of Synergetics the fundamental discover has been implemented. The universe, as a whole matter, from physical level - to biological and social level, has the property of self-organization, self-development. Also, it has been discovered, that self-organization algorithms have much common among each other in various systems of nature. Despite the external likeness of processes, equations during their mathematical description have practically coincided with each other. In these equations only physical content of sizes was different.

The term "Synergetics" (joint or cooperative action-translation from Greek) was first used by the English physiologist Sherrington in the study of the control of muscular systems from the side of the spinal cord. According to the theory of synergistic - any nonlinear system has the property of self-development. At a conference on synergistic issues in 1973, a German scientist H. Haken noted that self-organizing processes are observed in different systems of nature - in lasers, in the atmospheric vortex, in groups of wild animals, in the formation of complex molecules in chemical reactions, in the galaxy and in some social events - in the process of transition from less orderly to more organized. Collective, agreed processes take place in these systems. They behave like each other and subject to common mathematical regularities. $\mathrm{H}$. Haken also found the mathematical apparatus by which he was able to describe the process of self-organization of systems (Haken, 1983).

1. Stochastic theory - for description of misbalanced processes.

2. Bifurcation theory - for description of phase crossings. Haken in self-organization systems has divided their common characteristic - mutual co-ordination of its elements (cooperativeness) and has made common mathematical model of this event.

Two stages of developing of Synergetics are divided.

The age of dissipative structures. Mathematical apparatus of Synergetics was the theory of bifurcation and the theory of ordinary differential equations on this stage.

Some tasks were not solved on the first stage of Synergetics, such as general conditions of self-organization, which is changeable in concrete case.

He singled out three common features of systems self-organization:

1. Agreement, collectivity, and cooperation. Any collective process cannot come to self-organization independently, but only - by mutual agreement;

2. Systems can only be open that exchange energy or matter with the environment. For example, Benar's cells and laser radiation can only exist if they receive energy from the outside;

3. The systems are unbalanced. Unbalanced phase transitions can be attributed to phase transitions in lasers, the emergence of Benar cells; (Haken, 1983).

This theory was developed by (G.Nicolis, I.Antonio, A.Babloyants,V. Basios,I.Stengers and other scientists) representatives of the I. Prigogine School in Brussel, who tried to explore the systems of different natures (Physical, chemical, biological, social, etc.). The research determined the necessary conditions for the start of self-organization of systems:

1. The system must be open;

2. Processes must be in a state away from thermodynamic equilibrium;

3. It is necessary to detect and amplify fluctuations in the system that shake the old order and lead the system to a new order;

4. Self-organization relies on positive feedback (changes in the system are accumulated and strengthened by the system itself);

5. Self-organization can only begin in systems that have a sufficient (critical) number of interacting elements; (Prigogine, Stengers, 1984)

At the end of the twentieth century. Synergetic theory in education was developed by S.P. Kurdyumov, E.N. Knyazeva, N.V. Gaskova, L. Y. Zorin (considered the synergetic principles of integrating natural science and humanitarian education), K.Kh. Delokarov, F.D. Demidov, V.G. Budanov, A.D. Ursul (philosophical and methodological problems of education in a synergistic aspect), G.G. Malinetskiy (principles of self-organization of educational and training activities within the educational process), L.I. Novikova, V.P. Veryaskina, O. P. Melekhova, V.I. Arshinov (organization of reflection and communication in open educational systems), M.T. Gromkova, K.K. Kolin, I.A. Surin (the formation of a synergistic worldview and activity).

In the aspect of the theory of synergistic, in accordance with the sustainable, dynamic and effective development of the education system, in general, the basis of optimal human manufacture is the principles of fluctuation, coevolution, order parameters, and cooperation.

Let us discuss each of them in terms of raising students' learning motivation. 
The principle of fluctuations. The change caused by the current processes in the system is called fluctuation. In relation to the teaching process, this principle can be presented as follows: The subjects and the teachers' activity should be directed in the direction where the teaching process take a creative character. It becomes important for teachers to master the methods of self-education. Conditions must be created to enable the emergence of knowledge based on the creative process. Scientific discovery, high-level report, interesting lecture topic, teacher's attitude and so on - are fluctuations that can have a positive impact on the processes of the education system.

According to Prigogine, a human society has a high sensitivity to fluctuations - there is a non-linear relationship between the power of fluctuation and changes in the system. Fluctuations can be amplified by feedback, thereby causing system changes.

Order settings. To study the current processes in the system, from the set of its characteristic parameters, the socalled Managing settings, the nature of the change of which determines the nature of the system operation. H. Haken characterizes it with the following example: if the density of people at the subway crossing is insignificant, then people move smoothly, chaotically, as if they do not notice each other. As the density increases, they have regard for each other and take care of the new arrangement of movement - either left or right. Here the density is the ruling parameter.

The synergetic model introduces the principle of "invariance" in education technology. It offers a choice of multiple options. In these conditions, decision-making creates order parameters (fashion), which lead to the formation of a new orderly structure. In the case of education the parameter of order is the conception. The behavior of the system elements are subdued to the conception, and as a result, the positive feedback is obtained.

Information is provided to the system. This information is perceived differently by the elements of the system. The Part of the elements of the system uses it and evolves accordingly, while the other part remains behind these processes. Active elements are a kind of fashion of the system. They subject the rest of the elements of the system. Through these processes the system acquires its structure.

The principle of cooperation. The principle of cooperativeness mainly implies the agreed interaction of the subjects of the system. The focus is on the system as a whole and on its optimal development. With regard to education, this means obtaining synergy as a result of the agreed interaction of the subjects of education, operating in a single tempo mode. Self-organization is understood as the process of changing the interrelationship of elements, which is aimed at maintaining and developing the whole system and not its parts. The main characteristic of the emergence of the process of self-organization is cooperativeness. The system property no longer goes down to the arithmetic sum of the properties of the system elements; this is already a new feature that its elements do not have. This situation leads to further development of the system.

The principle of synchronous development. Subjecting students to a common goal (engaging in synchronicity) creates a dynamically stable, sustainable development system. The new topological correct combination of elements accelerates the development of both the unified system and its individual elements. The elements of the system begin to function at the same pace to the point where they have the ability to integrate another immediate environment into a given order.

We believe that the method of project development is of great importance for practical and laboratory training, it significantly raises the level of student self-organization in the teaching process. In the traditional approach, when a student solves tasks individually, the problem-solving time is extended accordingly, due to their different levels of preparation. Under the conditions of the design method, the process becomes more dynamic when jointly solving the task, at the same time, new hypotheses and different ways of solving the problem are born in the group, - that is students' self-learning, development and mutual learning. (Yakusheva, 2014).

Students' motivation for creative activities increases, which is of great importance for the teaching process. The result of the students' joint efforts outweighs the efforts of each of them individually. This is the main synergistic effect of collective creativity. This method is widely used in our teaching process. Small student groups are formed with 2-3 students.

The relationships that are formed between students during problem solving are an important stage in group self-organization.

Students' independent working and collaborative learning take place in small groups of students. The project is considered completed if each student-group member solves the task with equal quality and answers all the questions.

The synergistic effect of this method is expressed in the change of students' attitudes towards teaching, increases the motivation to acquire knowledge, the student develops skills to work independently and learn from each other, there is an opportunity to find more effective means of solving the task. At the same time, the basis for self-organization of the learning process is laid and learning becomes a requirement of students.

Mutual learning develops students' skills in expressing their opinion, asserting their own way of solving a task, drawing conclusions, and proposing future research.

The teacher is in the role of project organizer, consultant. Participates in the discussion of results, more effective student groups can be involved by the teacher in more serious scientific work and scientific conferences. Thus it can be said that the method of the project enhances the quality of teaching, forms the principles of relationship in the study group based on self-organization, introduces the principle of creativity and motivation in the teaching process, and the effect of student self-learning and mutual learning is enhanced. Courage of scientific activity and partnerships are formed with the teacher. With this approach, students acquire the knowledge and skills, which are necessary for professional activities.

They develop competencies such as problem solving, self-education, and social interaction opportunities. 


\section{CONCLUSION}

The conclusion can be ascertained about the direct dependence of civilization, sustainable development of the state, spiritual evolution of humanity from personality traits and the way a person achieves a high level of education. The formation of students' readiness for self-organization in the process of independent work at the university is possible only when you turn on student in this type of educational activity, which would simulate the conditions of highly efficient professional activity, corresponding to the level of the European standard.

At the turn of the XX- XXI centuries, the Georgian systems education were involved in complex economic processes, social, political and cultural transformations associated with both the transition to democratic forms of life and governance, and with inclusion in global structures: financial, economic, political technical, informational. This gives us an understanding that the strategic goal of domestic educational activity at this transitional stage is a change in the educational paradigm, which cannot be done without attracting the enormous methodological potential of post-non-classes scientific science, which is becoming a new picture of the world, the core of which is Synergetics.

Nonlinear science is being developed even today. International scientist conferences are regularly held on this theme. Books with series of Synergetics are established in publishing house "Shpringer", which has exceeded 100 volumes. Today, a number of scientific journals are devoted to nonlinear science: "Chaos", "Nonlinearity", "Physical Revies $E^{\prime}$. Scientific magazines establish articles on themes of Synergetics.

In the works of Academician I. Prangishvili, the principles and methods of the systems approach and the universal systemic laws that govern a significant part of natural and social systems are discussed (Gugushvili, 2003).

The main feature of synergy is its interdisciplinary nature. The latter means cooperation between different scientific directions.

We would like to hope that the views of synergistic and the new methods of approach in the field of education will help us to find the effective techniques of self-organization for such a long period of transition in Georgia.

\section{REFERENCES:}

Budanov,V., (2006). Methodology and principles of synergetics. http://law.sfu-kras.ru/attachments/article/4088/15budanov-fo-1-3-2006.pdf

Chapman, D. D., Adams, D., (2002). The quality of education: Dimensions and strategies. Education in Developing Asia 5:1-73

Cohen, L., Manion, L., \& Morison, K. (2007). Research Methods in Education. (6th ed.). London: Routledge.

Gugushvili, R., Khurodze, T., Imedadze T., (2003). Synergetics, text-book of XXI century GTU.

Haken, H., (1983). Synergetics Springer-Verlag Berlin Heidelberg New York Tokyo

http://norlx51.nordita.org/ brandenb/AstroDyn/progress/material/Haken83.pdf

Joppe, M., (2000). The Research Process. Retrieved January 16, 2017, from http://www.ryerson.ca/ mjoppe/rp.htm

Kösterelioğlu, M. and Kösterelioğlu, I., (2015). Effects of high school students' perceptions of school life quality on their academic motivation levels. Educational Research and Reviews 10(3): 274-281.

Prigogine, I; Stengers, I., (1984). Order out of Chaos: Man's new dialogue with nature. Flamingo ISBN 0-00-654115-1

Saepudin, A. and Marlina, A., (2013). The effects of institution service quality on student satisfaction of Smpn 3 Cibadak, Sukabumi. International Journal of Scientific \& Technology Research 2(3): 162-172.

Sesadze, V., Kekenadze, V., Chikadze, G., (2013).- "Synergetics, research of economical processes", Tbilisi.

Sesadze, V., Sesadze, N., (2004). Synergetic - Sinthesis of Nonlinear Systems . CTU, Tbilisi.

Yakusheva, D., (2014). Synergetic Approarch in the Development of Professional of a Modern Thacher http://spkurdyumov. ru/education 